\title{
Characteristics of the Cloud Top Heights of Marine Boundary Layer Clouds and the Frequency of Marine Fog over Mid-Latitudes
}

\author{
Hideaki KAWAI, Shoukichi YABU \\ Meteorological Research Institute, Tsukuba, Japan \\ Yuichiro HAGIHARA \\ Research Institute for Applied Mechanics, Kyushu University, Fukuoka, Japan \\ Tsuyoshi KOSHIRO \\ Meteorological Research Institute, Tsukuba, Japan \\ and \\ Hajime OKAMOTO \\ Research Institute for Applied Mechanics, Kyushu University, Fukuoka, Japan
}

(Manuscript received 13 March 2015, in final form 1 June 2015)

\begin{abstract}
The cloud top height of marine boundary layer clouds (MBLCs) in the mid-latitudes has received less attention than that of subtropical MBLCs and is investigated here using cloud mask data, which were based on observations from the cloud-aerosol lidar and infrared pathfinder satellite observation (CALIPSO) satellite. This study provides a comprehensive overview of the observational characteristics of variations in cloud top height of MBLCs and fog frequency over the mid-latitudes. Seasonal variations in the cloud top height of mid-latitude MBLCs as well as the differences in these seasonal variations between the Northern and Southern hemispheres were determined. For example, over the North Pacific, the cloud top height is high in winter (up to $1800 \mathrm{~m}$ ) but low in summer (down to $800 \mathrm{~m}$ ), whereas in the Southern Hemisphere, the seasonal variation is not well defined, with heights ranging from 1300 to $1500 \mathrm{~m}$. While clear seasonal variations in the frequency of fog occurrence are found over the North Pacific and the northwest Atlantic, the fog frequency over the Southern Ocean is almost constant irrespective of the season. High correlations were found between the MBLC top height and stability indexes and between the fog frequency and some surface parameters such as temperature difference between the surface air and the sea surface. The latitudinal variations in the cloud top height of MBLCs in summer and winter over the Southern Ocean were compared with those over the North Pacific. The difference in cloud top heights between nighttime and daytime is also presented.
\end{abstract}

Keywords boundary layer cloud; mid-latitude; cloud top height; fog; satellite lidar

Corresponding author: Hideaki Kawai, Meteorological

Research Institute, 1-1 Nagamine, Tsukuba, Ibaraki

305-0052, Japan

E-mail: h-kawai@mri-jma.go.jp

(C)2015, Meteorological Society of Japan 


\section{Introduction}

Marine boundary layer clouds (MBLCs) are one of the most important cloud contributors to the global radiation budget because of their large shortwave radiative effects (e.g., Klein and Hartmann 1993). Not only MBLCs in the subtropics, where solar insolation is relatively large, but also MBLCs in the mid-latitudes play an important role in determining the global radiation budget. For example, it has been recognized recently that a significant lack of clouds over the Southern Ocean is a serious problem in most climate models and causes huge biases in shortwave radiative flux over the Southern Ocean, especially in the summer months (Trenberth and Fasullo 2010).

A number of studies have examined aspects of mid-latitude MBLCs. Klein and Hartmann (1993) comprehensively discussed the characteristics of global low cloud fractions, including mid-latitude MBLCs and their meteorological fields. Wood and Bretherton (2006) defined a stability index that has a high correlation with the cloud fraction of stratiform low clouds, including mid-latitude low clouds. Several studies investigated the morphology of mid-latitude low clouds and their relationship with meteorological fields using synoptic surface observation data (e.g., Norris 1998a, b; Norris and Klein 2000; Koshiro and Shiotani 2014). However, MBLCs over the mid-latitudes (ca. $30^{\circ}$ to $65^{\circ}$ ) have not been investigated as intensively as subtropical MBLCs. Therefore, it is important to understand the various characteristics of mid-latitude MBLCs in detail, and such an understanding will also be crucial if we are to improve the parameterization of MBLCs in models.

One of the important features of clouds is their vertical structure, including the cloud top height. However, it has been impossible even to investigate cloud top heights globally and in detail because estimates of cloud top height derived from conventional satellite infrared imager data include huge uncertainties. One of these uncertainties arises because a vertical profile of temperature must be assumed when the observed cloud top temperature is converted to height. When the cloud is not optically thick enough, this technique of estimating the cloud top height from the brightness temperature cannot be used. Furthermore, even if the cloud is optically thick, the cloud height is overestimated when there is an inversion layer at the top of the clouds (e.g., Holz et al. 2008). Garay et al. (2008) showed a remarkable example in which a cloud top height retrieved from the Moderate Resolution Imaging Spectroradiometer (MODIS; Platnick et al. 2003) for a low cloud was $3890 \mathrm{~m}$, whereas the cloud top height measured by radiosonde was $1354 \mathrm{~m}$. However, with the advent of the radar satellite CloudSat (Stephens et al. 2008) and the lidar satellite cloud-aerosol lidar and infrared pathfinder satellite observation (CALIPSO; Winker et al. 2009) in 2006, it became possible to observe the global distribution of accurate cloud top heights and even the vertical profile of the clouds. As for the cloud top heights of subtropical MBLCs, there have been several studies using the CALIPSO data; e.g., Ahlgrimm et al. (2009), Ahlgrimm and Köhler (2010), and Wang et al. (2011), although there have been no such studies focusing on mid-latitude MBLCs.

The satellite especially important with respect to the detailed investigation of low clouds is CALIPSO because it can observe low clouds even to altitudes below $1 \mathrm{~km}$ and with better vertical resolution than CloudSat. However, there is an abundance of aerosols in the lower troposphere, so it is necessary to appropriately remove contamination by aerosol signals from the low-cloud signals observed by CALIPSO. Hagihara et al. (2010) developed a sophisticated algorithm to eliminate aerosol signals from the CALIPSO backscatter data and created cloud mask data (referred to as the KU cloud mask; i.e., the Kyushu University cloud mask product), which they retrieved from the CloudSat and CALIPSO data. Here, we use KU cloud mask data to investigate the vertical structure of low clouds because they are likely to be the most appropriate data for the detailed investigation of such clouds.

The purpose of this paper is to use cloud mask data to comprehensively describe the various characteristics of mid-latitude MBLCs, and this will be the first global study related to mid-latitude MBLCs. We show the seasonal variations in the cloud top heights of mid-latitude MBLCs and also highlight the differences in the characteristics of the mid-latitude MBLCs between the Northern and Southern hemispheres. In addition, the frequency of fog occurrence, where fog is defined as cloud lower than $240 \mathrm{~m}$, is examined because a global distribution of marine fog is also an important target of study; it affects maritime traffic in human lives and the sky obscuring marine fog is a contributor to the earth radiation budget. We compared the latitudinal variations in mid-latitude MBLCs over the Southern Ocean and the Northern Pacific during the summer and winter seasons, and examined the differences in the cloud top heights between daytime and nighttime. Moreover, the relationships among the cloud top heights of mid-latitude MBLCs (also the frequency of fog occurrence) and meteorological factors are briefly investigated using European Centre for Medium-Range Weather Forecasts (ECMWF) Re-Analysis Interim (ERA-Interim) data to develop an understanding of these seasonal cycles and the differences between the two hemispheres.

Subsection 2.1 describes the data used in this study 
and its processing, and the basic features of the data with regard to the distributions of boundary layer cloud top and fog are presented in Subsection 2.2. The results of the analysis related to the cloud top height of mid-latitude MBLCs and fog are given in Section 3 , including the seasonal variations (3.1), the latitudinal variations (3.2), and the diurnal variations (3.3). Discussions are given in Section 4, including relationships of cloud top height and fog frequency with meteorological factors. A summary is provided in Section 5.

\section{Data, the processing, and the basic features}

\subsection{Data and the processing}

The cloud mask schemes used here were originally developed and tested for the shipborne $94-\mathrm{GHz}$ cloud radar and lidar system described by Okamoto et al. (2007) for the mid-latitudes and were further tested in the tropical western Pacific by Okamoto et al. (2008). The schemes were then modified to develop a combined CloudSat-CALIPSO cloud mask and applied to the three months of data covering September to November 2006, and the resulting vertical distributions of zonal mean cloud fractions and cloud coverage were analyzed (Hagihara et al. 2010).

The KU cloud mask datasets include four different types of cloud mask data. Dataset C1 is based on CloudSat data only; C2 is based on CALIPSO data only; the C3 dataset is "CloudSat and CALIPSO data," where grids in which both the $\mathrm{C} 1$ and $\mathrm{C} 2$ averaged mask values exceed 0.5 are considered to be with cloud; and the $\mathrm{C} 4$ dataset is "CloudSat or CALIPSO data," where grids in which one of the values from the $\mathrm{C} 1$ and $\mathrm{C} 2$ averaged mask values exceeds 0.5 are considered to be with cloud (Hagihara et al. 2010). The C4 data are potentially the most useful for cloud vertical profile studies because clouds that cannot be detected by radar may be detected by lidar and vice versa, in the $\mathrm{C} 4$ data. However, CloudSat cloud mask data is unreliable lower than $720 \mathrm{~m}$ because of surface clutter, even after clutter rejection is applied (CloudSat 2B GEOPROF R04 Quality Statement, May 2007, available at http:// www.cloudsat.cira.colostate.edu/data-products/level$2 b / 2 b$-geoprof?term $=42$ ), and the CALIPSO cloud mask presumably capture any visible cloud top.

Therefore, the $\mathrm{C} 2$ data were used here to investigate mainly the cloud top heights of mid-latitude MBLCs. In contrast to CloudSat, CALIPSO can capture clouds that are fairly near the surface, even below heights of $240 \mathrm{~m}$. The vertical resolution of the cloud mask data is $240 \mathrm{~m}$, and the horizontal resolution is $1.1 \mathrm{~km}$.

One of the difficulties in studies related to mid-latitude low clouds is that upper clouds often appear in the mid-latitudes and can affect the statistics related to the low clouds; for example, the upper cloud fraction reduces the low cloud fraction observed by satellites. However, data were eliminated from our statistical analysis if there were clouds present above $5 \mathrm{~km}$, and the statistics include only those data columns with no clouds above $5 \mathrm{~km}$. Therefore, in the present study, we can ignore the influence of upper clouds because our statistics were calculated only over areas free of high clouds (i.e., the statistics were normalized by the high-cloud-free area). Typically, the upper cloud fraction is $40 \%-50 \%$, the clear area fraction is $10 \%-20$ $\%$, and the fraction of low cloud not covered by upper clouds is $30 \%-50 \%$ in mid-latitude areas investigated in the present study, as can be seen in Fig. 8 afterward. Although we cannot reveal the characteristics of height of cloud tops that are shielded by upper clouds, it is still important to obtain only those of low clouds with clear skies above, because low clouds not covered by upper clouds have a much more important role in the global radiation budget.

The 20-km mesh global monthly climatologies of 3D data (including the occurrence frequencies of cloud top and cloud fraction) and 2D data (including upper cloud fraction, clear area fraction, low cloud fraction over no-upper-cloud area, as well as medians of cloud top height) were created first to facilitate the data processing and analysis, and were based on data for the period 2007-2009. The median data were calculated to eliminate outliers and were used for the analysis. Moreover, for the calculation of average cloud top height (in Figs. 6, 7, 8, 10), the averages were calculated using the data from which the top 25 $\%$ and bottom $25 \%$ of the data were eliminated in order to obtain typical values.

\subsection{Basic features of the data \\ a. Boundary layer clouds}

Before we look at the various characteristics of mid-latitude MBLCs cloud top height obtained from these data, it is worth outlining the basic features of the dataset, including horizontal patterns, and demonstrating that it does not include obviously unrealistic cloud mask data. Figure 1 shows the relative frequencies of occurrence of cloud top height in each altitude bin for columns with no clouds above $5 \mathrm{~km}$, calculated from the KU cloud mask for July. The term "relative frequency" indicates that the frequency was calculated only for cloudy parts in areas without upper clouds. In the lowest $(0-240 \mathrm{~m})$ bin, the data show frequent cloud top occurrence over the North Pacific and areas near Newfoundland Island, where fog is common (discussed in Subsection 2.2.b in more detail), and do not show false cloud top occurrence in areas where fog is unlikely, such as tropical oceans. In the second-lowest (240-480 m) bin, the data show 

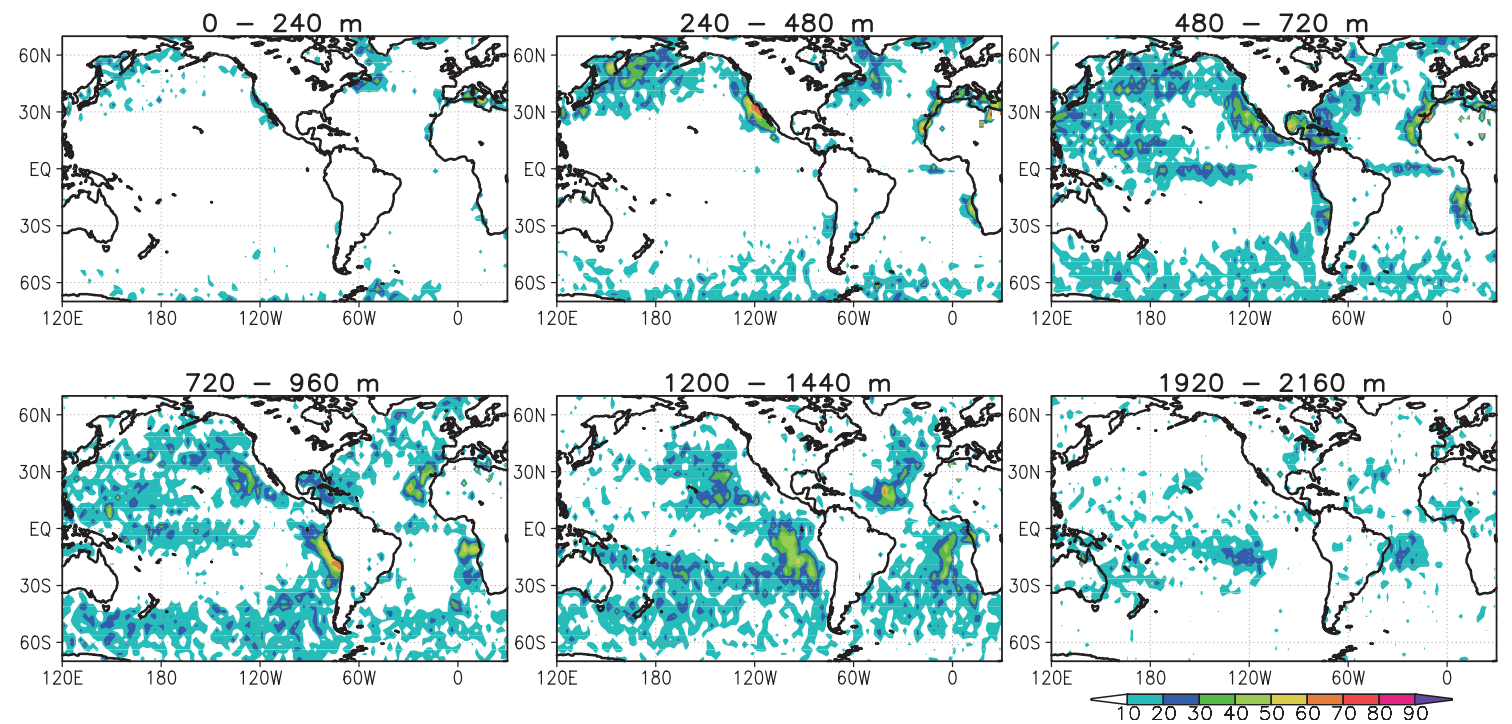

Fig. 1. Relative frequencies (\%) of occurrence of cloud top height in each altitude bin for July. From upper left, altitude bins plotted are as follows: 0-240 m, 240-480 m, 480-720 m, 720-960 m, 1200-1440 m, and 1920-2160 m. For the period 2007-2009, only data with no clouds at altitudes above $5 \mathrm{~km}$ were used to calculate the statistics (and for all figures hereafter).

frequent cloud top occurrence in areas adjacent to California, which commonly experiences extremely low clouds with a base of $300-400 \mathrm{~m}$ and a top at 500-600 m (e.g., Albrecht et al. 1988; Blaskovic et al. 1991; Duynkerke and Teixeira 2001). The thirdlowest bin, at 480-720 m, has its cloud top beginning to occur in areas adjacent to Peru, where low clouds are also common, but it is known that the cloud layer is higher compared with areas near California (e.g., Bretherton et al. 2010). In the fourth lowest bin, at $720-960 \mathrm{~m}$, frequent cloud top occurrence is found off California and off Peru, and a low-frequency area of cloud top occurrence starts to appear in areas adjacent to California. In the 1200-1440 m bin, areas of frequent cloud top occurrence prevail away from the continents in the subtropics and the low frequency zone near California becomes broader. In the 1920 $2160 \mathrm{~m}$ bin, very few cloud tops were recorded off California or Peru. All of these characteristics are totally consistent with our existing knowledge of the distribution of low clouds (e.g., Norris 1998b; Wang et al. 2011). The characteristics of cloud top height over mid-latitude areas are discussed later in detail.

As another brief check, the geographical variations in the cloud top height of the subtropical MBLCs from the KU cloud mask data were also reviewed because these variations are well known from numerous previous studies. Figure 2 shows vertical sections of the relative frequency of cloud top height occurrence along $30^{\circ} \mathrm{N}$ off California and $20^{\circ} \mathrm{S}$ off
Peru for July. The mask data capture that the cloud layers are low near the coasts and gradually increase in height offshore. The typical characteristic that the cloud layers are lower near California than near Peru is also well captured in the data. Karlsson et al. (2010) showed cloud-top-height evolution along the GPCI line (GCSS/WGNE Pacific cross-section intercomparison; GCSS: GEWEX cloud system study; WGNE: working group on numerical experimentation; GEWEX: Global Energy and Water Exchanges Project; see Teixeira et al. 2011) off California using Multi-angle Imaging SpectroRadiometer (MISR) data. Stratocumulus cloud structure along $20^{\circ} \mathrm{S}$ observed by a cloud radar and upward-pointing lidar aboard an aircraft is shown in Bretherton et al. (2010), Rahn and Garreaud (2010), and Abel et al. (2010). The results in Fig. 2 are consistent with those previous studies not only qualitatively but also quantitatively, and this consistency supports our use of the data to study the vertical structure of mid-latitude MBLCs, which has been less investigated.

\section{b. Fog}

Global observations of fog over the ocean are remarkably difficult because: (1) there are few observation sites that can observe visibility or the height of the cloud base over the ocean; (2) when using conventional satellites (e.g., imagers) it is impossible to observe fog if there are upper clouds present, even if they are boundary layer clouds; and (3) even 

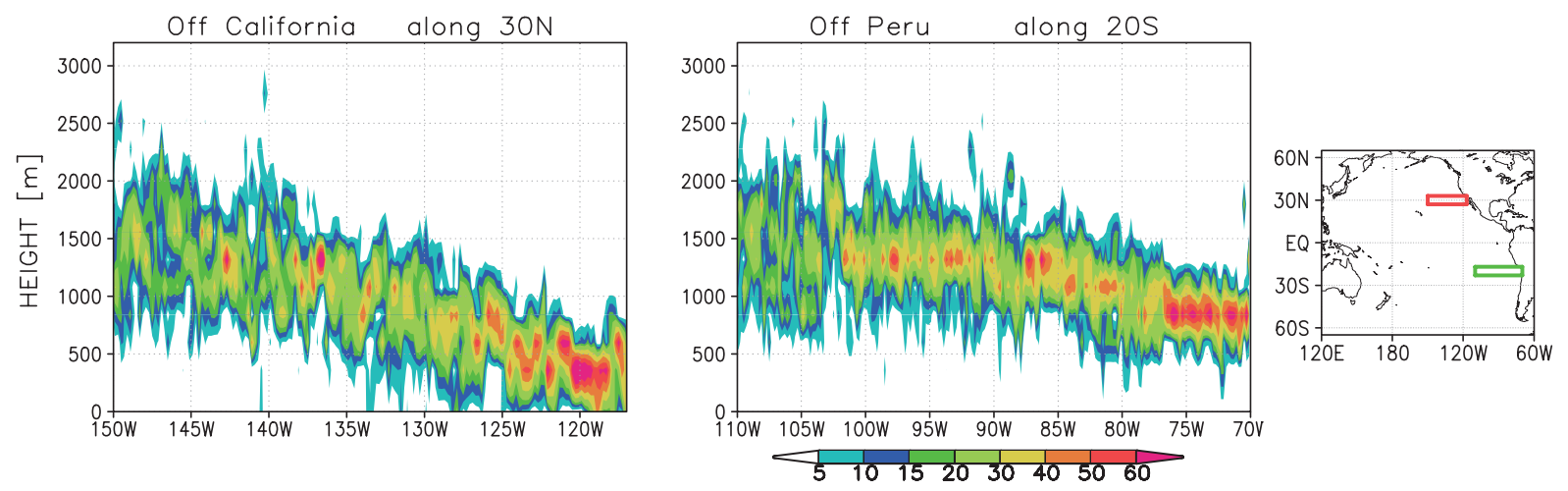

Fig. 2. Vertical sections of relative frequencies (\%) of cloud top height occurrence along $30^{\circ} \mathrm{N}$ off California (left) and along $20^{\circ} \mathrm{S}$ off Peru (middle) for July. The locations are indicated on the map (red: $30^{\circ} \mathrm{N}$ off California, green: $20^{\circ} \mathrm{S}$ off Peru), and the latitudinal width of the bands is $6^{\circ}$.

when there are no clouds over the fog and the visible channel can detect the clouds near the surface, it is almost impossible to identify whether the altitude of the clouds is about $100 \mathrm{~m}$ (possibly fog) or about 500 $\mathrm{m}$ (not fog), because the estimation of altitude using the infrared channel is not sufficiently accurate. Even after the advent of satellite radar and lidar, the second problem still remains because CloudSat cannot observe clouds lower than $720 \mathrm{~m}$ and CALIPSO cannot penetrate thick clouds. However, the third problem was solved by the advent of CALIPSO now, and so we tried to extract information regarding global fog distribution using the cloud mask data in the present study.

The frequency of fog occurrence, which is defined as cloud occurrence in the $0-240 \mathrm{~m}$ bin in the present study, calculated from the cloud mask data was compared with the frequency simulated by the global spectral model (GSM; Japan Meteorological Agency (JMA) 2013) of JMA for 2007-2009, and the climatology derived from shipboard observations for 1954-2008 calculated using the Extended Edited Cloud Report Archive (EECRA; Hahn and Warren 2009; Eastman et al. 2011). The frequencies for July are compared in Fig. 3, because fog occurrence over mid-latitude oceans in the Northern Hemisphere is known to be the highest in July. The procedure of Teixeira (1999) was used to calculate the fog occurrence in the model, where fog occurrence is regarded as the occurrence of cloud water content greater than $0.016 \mathrm{~g} \mathrm{~kg}^{-1}$ in the lowest model layer. As Teixeira (1999) discussed in the comparison of climatologies of fog occurrence between the ECMWF model simulation and shipboard observations (Warren et al. 1988), regions that experience frequent fog, such as around the Kamchatka Peninsula, near Newfoundland Island, north of Iceland, and the Arctic Ocean along the Eurasian continent, are consistent among the KU cloud mask, the JMA-GSM simulation, and the shipboard climatology. Although it was not possible to obtain fog occurrence data over the Southern Ocean based on shipboard observations because the sample number for the area in winter was too small, CALIPSO can observe clouds over the Southern Ocean in the winter and the KU cloud mask can provide some information for this area. Fog-occurrence regions occur consistently at latitudes higher than $40^{\circ} \mathrm{S}$ in both the KU cloud mask data and the JMA-GSM simulation, although fog-free regions are seen only in the JMA-GSM simulation at latitudes higher than $60^{\circ} \mathrm{S}$.

The fog-occurrence frequency derived from the cloud mask data is a lower limit of the estimation because CALIPSO cannot observe clouds that occur below thick clouds. The occurrence frequency of cloud top height below $480 \mathrm{~m}$ is also shown in Fig. 3, and the distribution is quite similar to the fog occurrence frequency from the lowest bin cloud mask (this characteristic is discussed later). These three climatologies of fog-occurrence frequency, which are totally independent, provide similar results, and this supports the reliability of fog frequencies derived from the KU cloud mask data, even though it is an estimated lower limit.

\section{Results}

In Section 2, we confirmed that the widely reported characteristics (including the vertical structure) of subtropical MBLCs and fog climatology are also found in our data, and we therefore use these data to investigate the characteristics of cloud top height of mid-latitude MBLCs, which have yet to be studied closely. The results of our analysis of mid-latitude MBLCs are provided as follows: the seasonal varia- 

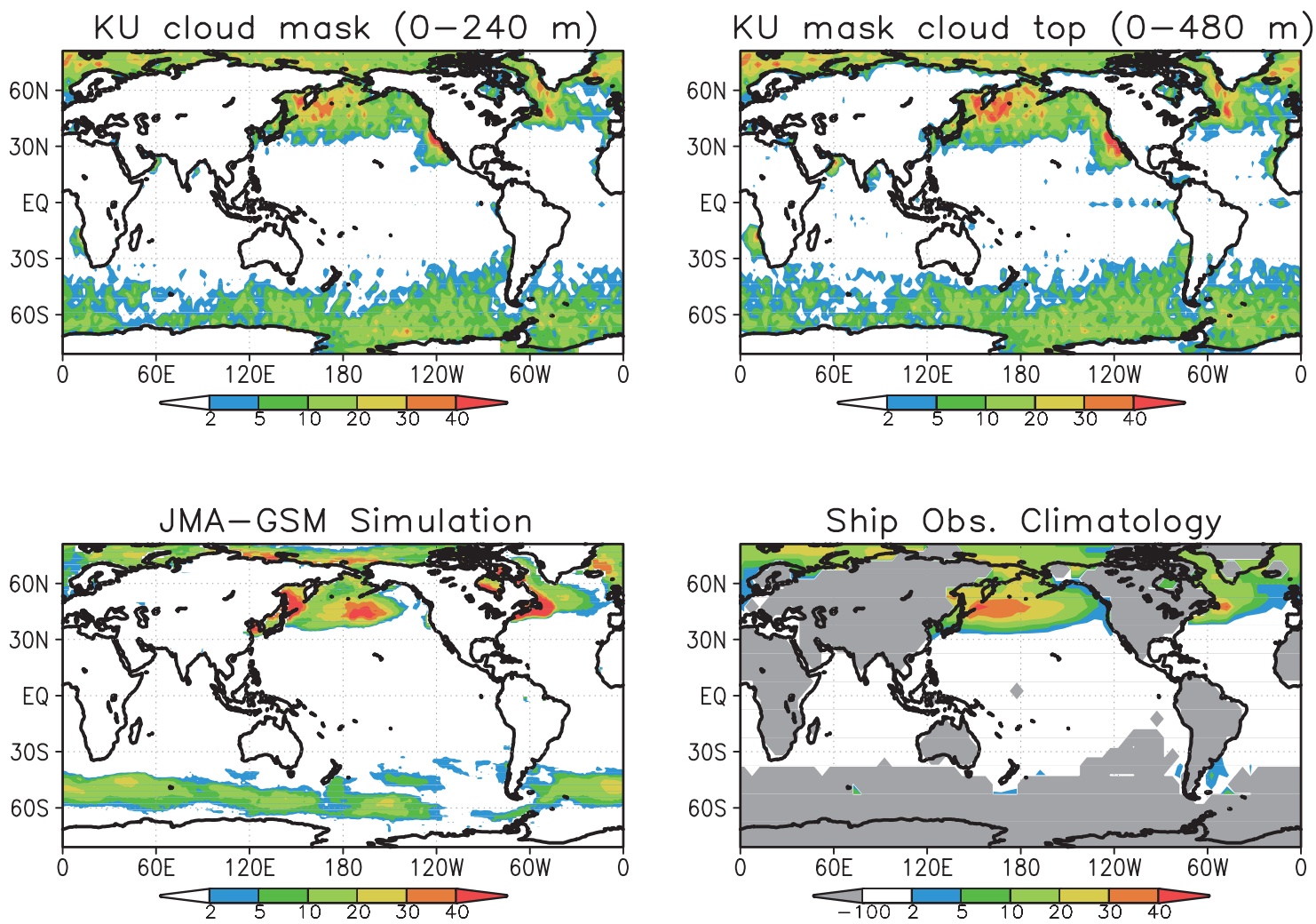

Fig. 3. Occurrence frequencies (\%) of fog (0-240 $\mathrm{m}$ bin, top left) and cloud top height lower than $480 \mathrm{~m}$ (top right) derived using the KU cloud mask and the JMA-GSM simulation (bottom left) for July and based on data from 2007 to 2009. Shipboard observational climatology for July (1954-2008) is also shown (bottom right), where the ocean grids are shaded gray when the sample number was less than 100 for a $5^{\circ} \times 5^{\circ}$ grid (longitudinal width of the grid boxes poleward of $50^{\circ}$ is increased to maintain approximately equal areas in the boxes).

tions (3.1), the latitudinal variations (3.2), and the diurnal variations (3.3).

\subsection{Seasonal variations in cloud top height and fog}

Figure 4 shows the areas investigated in the present study. There are four areas in the mid-latitudes, with three in the Northern Hemisphere (the North Pacific, the northwest Atlantic, and the northeast Atlantic), and one in the Southern Hemisphere (the Southern Ocean zonal area), as well as two areas in the subtropics (off California and off Peru). These areas basically have large low cloud fraction (e.g., Klein and Hartmann 1993) and include fog-frequent mid-latitude areas shown in Section 2. The northeast Atlantic area is selected for comparison with the northwest Atlantic area because there are clear contrasts between them in the low cloud fraction and fog frequency climatologies. Vertical profiles of the relative frequency of occurrence of cloud top height for the North Pacific and the Southern Ocean areas are shown in Fig. 5. The term "relative frequency" indicates that the profile of the frequency was calculated only for cloudy parts in areas without upper clouds as mentioned above, and therefore, it means that the probability density function (PDF) of cloud top height is normalized. It is clear from the figure that the cloud top height over the North Pacific is fairly low in summer, but high in winter; in contrast, the seasonal difference over the Southern Ocean is very small. Figure 5 also shows some of the fundamental features of the data; for example, the frequency of cloud top height above $2500 \mathrm{~m}$ is extremely low for clouds whose cloud top height is below $5 \mathrm{~km}$. The width of the PDF is evidently narrower in summer over the North Pacific than in winter and over the Southern Ocean.

The top left panel in Fig. 6 shows the seasonal variation in cloud top height for all mid-latitude areas shown in Fig. 4; it is well defined in the Northern Hemisphere, especially over the North Pacific and the 


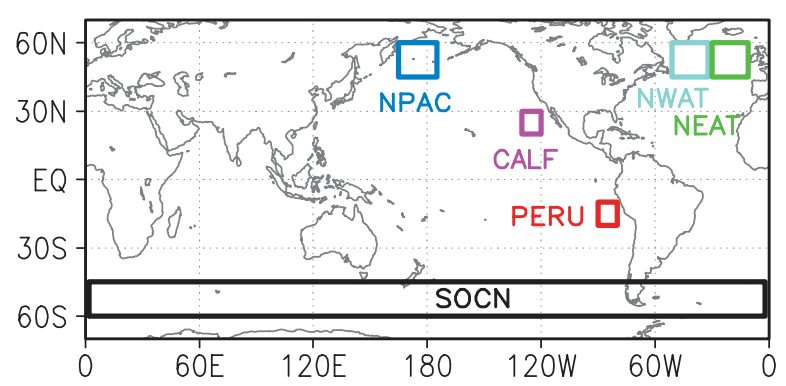

Fig. 4. Areas investigated in the present study: the North Pacific (NPAC; blue; $165^{\circ} \mathrm{E}-175^{\circ} \mathrm{W}$, $\left.45^{\circ} \mathrm{N}-60^{\circ} \mathrm{N}\right)$, the Southern Ocean (SOCN; black; $\left.0^{\circ} \mathrm{E}-360^{\circ} \mathrm{E}, 45^{\circ} \mathrm{S}-60^{\circ} \mathrm{S}\right)$, the northwest Atlantic (NWAT; light blue; $30^{\circ} \mathrm{W}-50^{\circ} \mathrm{W}, 45^{\circ} \mathrm{N}-60^{\circ} \mathrm{N}$ ), the northeast Atlantic (NEAT; green; $10^{\circ} \mathrm{W}-$ $30^{\circ} \mathrm{W}, 45^{\circ} \mathrm{N}-60^{\circ} \mathrm{N}$ ), off California (CALF; pink; $\left.120^{\circ} \mathrm{W}-130^{\circ} \mathrm{W}, 20^{\circ} \mathrm{N}-30^{\circ} \mathrm{N}\right)$, and off Peru (PERU; orange; $80^{\circ} \mathrm{W}-90^{\circ} \mathrm{W}, 10^{\circ} \mathrm{S}-20^{\circ} \mathrm{S}$ ).

northwest Atlantic. Over the North Pacific, cloud top height is high (up to $1800 \mathrm{~m}$ ) in winter and low (down to $800 \mathrm{~m}$ ) in summer. The amplitude of this seasonal variation is smaller over the northeast Atlantic, but the seasonal variation can still be found. In contrast, the seasonal variation over the Southern Ocean is not well defined. The top right panel in Fig. 6 shows the seasonal variation in the frequency of fog, defined as the occurrence frequency of the cloud in the lowest $(0-240 \mathrm{~m})$ bin. There are clear peaks in fog occurrence in summer for the North Pacific (NPAC) and the northwest Atlantic (NWAT), whereas there are no seasons with frequent fog over the northeast Atlantic (NEAT) or over the Southern Ocean (SOCN). To understand the fog frequency in more detail, frequencies of several vertical patterns of cloud mask near surface, which are shown in the bottom right panel in Fig. 6, are calculated individually, and the seasonal variations are shown in the bottom left panel in Fig. 6 . The contribution of clouds with top height in the lowest bin (0-240 m, long dashed line in the bottom left panel, corresponding to (a) in the schematic at the bottom right panel) to "fog" frequency (solid line, (a) $+($ c $)+(d)$ ) is less than half, but these extremely low clouds show seasonal variations similar to those in fog. The panel also shows that the occurrence frequency of clouds that have a cloud mask in the lowest bin and whose top is below $480 \mathrm{~m}$ (short dashed line, (a) $+(\mathrm{c})$ ) is almost equivalent to that of "fog" in our analysis, and the occurrence frequency of clouds whose top is below $480 \mathrm{~m}$ (dotted line, (a) $+(b)+(c))$ is also almost identical to that of "fog," though the frequency is a little higher than that of fog.

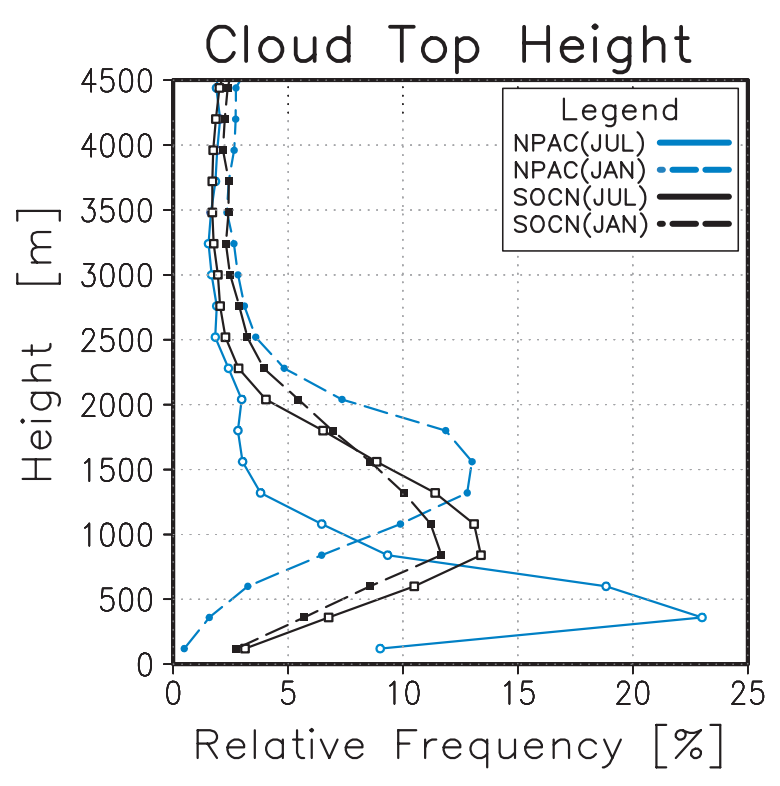

Fig. 5. Vertical profiles of the relative frequency of occurrence of cloud top height. Profiles for NPAC (blue) and SOCN (black) are shown for July (solid line) and for January (dashed line).

\subsection{Latitudinal variations in cloud top height in the mid-latitudes}

Several studies have examined the cloud top height of clouds over the Southern Ocean. Haynes et al. (2011) found that cloud regimes that are categorized as clouds with mid-level tops by the ISCCP (international satellite cloud climatology project; Rossow and Schiffer 1999) classification arise very frequently around, and southwards of, $60^{\circ} \mathrm{S}$. Using CloudSat and CALIPSO data, they also found that these regimes are a mixture of low and upper clouds. Bodas-Salcedo et al. (2012) determined the frequency of occurrence of each cloud regime, which was categorized using the ISCCP cloud top pressure, around Southern Ocean cyclones using a composite technique. Here, we investigated the characteristics of MBLCs over the Southern Ocean whose cloud top was lower than $5 \mathrm{~km}$ and compared them with the characteristics of MBLCs over the North Pacific during the summer and the winter.

Figure 7 shows the latitudinal variations in the cloud top height of mid-latitude MBLCs over the Southern Ocean (averaged over $0^{\circ} \mathrm{E}-360^{\circ} \mathrm{E}$ ) and the North Pacific (averaged over $165^{\circ} \mathrm{E}-165^{\circ} \mathrm{W}$ ) in summer and winter. Cloud top height is low (ca. 850 m) and almost constant over the North Pacific during the boreal summer. In contrast, cloud top height is higher over the Southern Ocean during the austral 

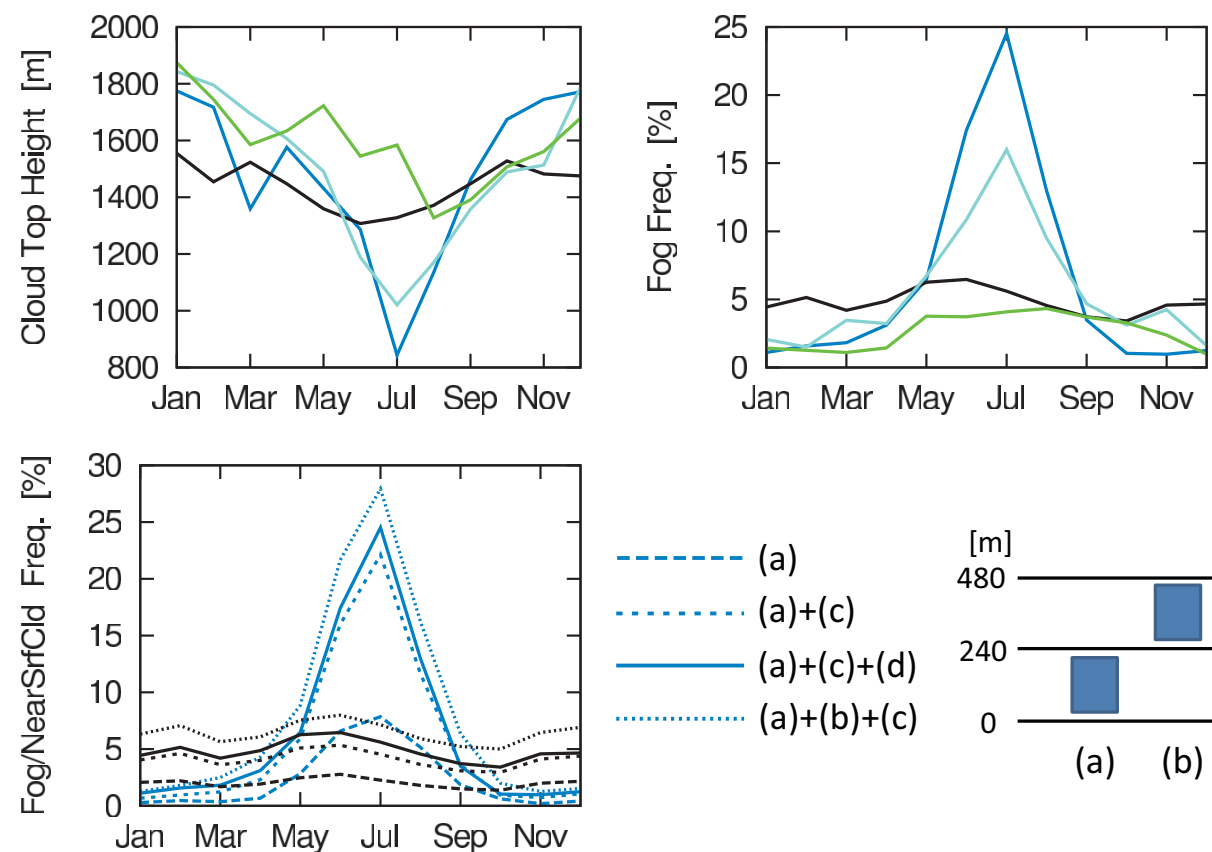

(a)

(a)+(c)

$(a)+(c)+(d)$

$(a)+(b)+(c)$

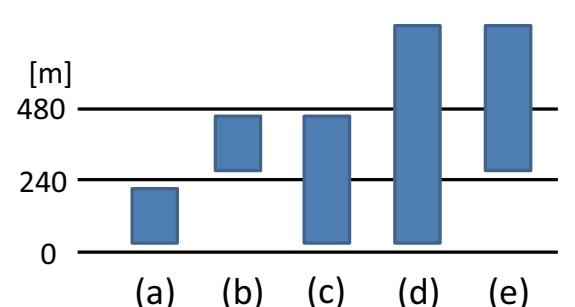

Fig. 6. Seasonal variations in cloud top height (top left) and frequency of fog (top right). Data for NPAC (blue), SOCN (black), NWAT (light blue), and NEAT (green) are shown. In the bottom left panel, four lines show occurrence frequencies of clouds whose top height is in the lowest bin (0-240 m, long dashed line, corresponding to (a) in the schematic of vertical patterns of cloud mask at the bottom right panel), clouds which have cloud mask in the lowest bin and whose top is below $480 \mathrm{~m}$ (short dashed line, (a) $+(\mathrm{c})$ ), clouds which have cloud mask in the lowest bin (corresponds to "fog," solid line, (a) + (c) + (d)), and clouds whose top is below $480 \mathrm{~m}$ (dotted line, (a) $+($ b) $+($ c) ) for NPAC and SOCN.

summer than over the North Pacific during the boreal summer; it increases polewards from $40^{\circ} \mathrm{S}$ (ca. 1200 m) to $65^{\circ} \mathrm{S}$ (ca. $1900 \mathrm{~m}$ ). In winter, cloud top height is high (ca. $1800 \mathrm{~m}$ ) over the North Pacific and starts to decrease at $55^{\circ} \mathrm{N}$ down to about $1200 \mathrm{~m}$ at $60^{\circ} \mathrm{N}$. In contrast, cloud top height is almost constant at around $1400 \mathrm{~m}$ over the Southern Ocean in winter. Note that as for winter over the Southern Ocean, there are two components at latitudes higher than $55^{\circ} \mathrm{S}$ : one is the cloud population with a top height below $1500 \mathrm{~m}$ and decreasing in altitude poleward, and the other is a poleward increase in the frequency of cloud top height above $2000 \mathrm{~m}$ (Fig. S1). The latitudinal variations for each season are totally different between the Northern and Southern hemispheres.

\subsection{Diurnal variations in cloud top height}

It is known that the cloud fraction and cloud water content of MBLCs show clear diurnal variations (e.g., Duynkerke and Teixeira 2001; Rozendaal et al. 1995). However, the diurnal variations in the vertical structure of MBLCs have yet to be studied closely, and there has been no detailed global scale investi-
N. Pacific 165E-165W， Southern Ocean Zonal

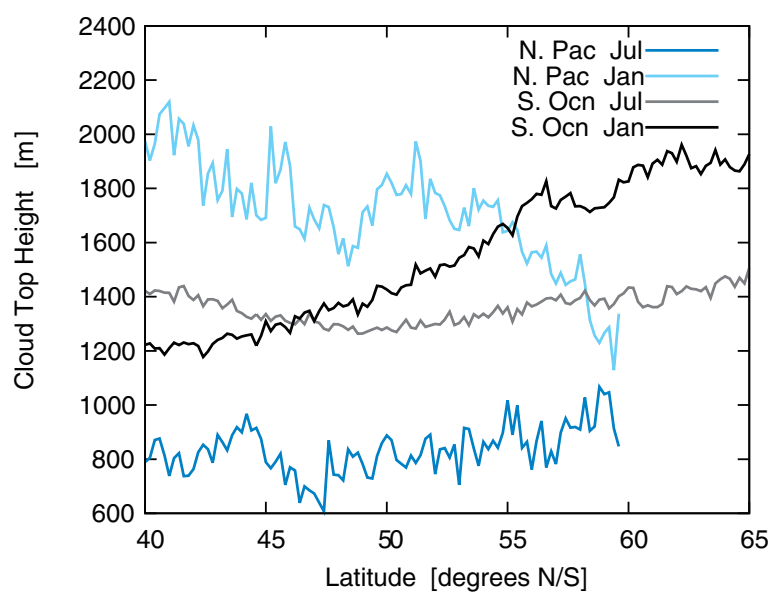

Fig. 7. Latitudinal variations in cloud top height over the North Pacific (averaged over $165^{\circ} \mathrm{E}-165^{\circ} \mathrm{W}$, blue: July, light blue: January) and over the Southern Ocean (averaged over $0^{\circ} \mathrm{E}-360^{\circ} \mathrm{E}$, grey: July, black: January). Latitude increases to the right for both the North Pacific and the Southern Ocean. 

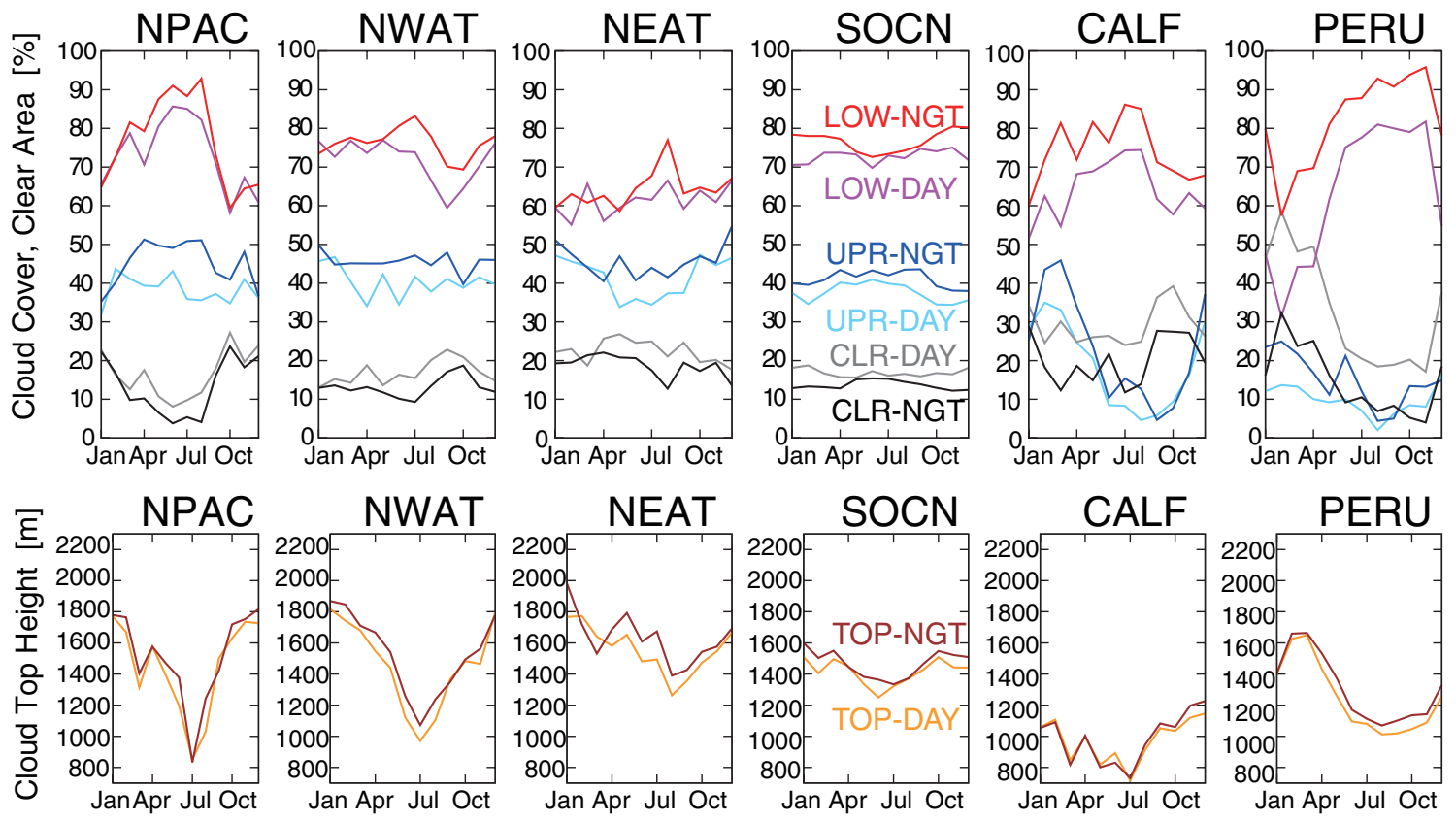

Fig. 8. In the top panels, upper cloud fraction (daytime: light blue; nighttime: blue), clear area fraction (daytime: gray; nighttime: black), and low cloud fraction over no-upper-cloud area (daytime: pink; nighttime: red) are shown (\%). In the bottom panels, cloud top heights (daytime: orange; nighttime: brown) are shown (m). From the left, the data from NPAC, NWAT, NEAT, SOCN, CALF, and PERU are shown. Horizontal axis: months.

gation of that of mid-latitude MBLCs. The CloudSat and CALIPSO satellites have daytime and nighttime orbits whose local times are around 13:30 and 01:30, respectively. Therefore, we can compare these data to detect diurnal variations in the cloud top heights.

Before discussing the diurnal variations in the vertical structure of low cloud, we will mention the diurnal variations in the low cloud fraction. The top panels in Fig. 8 show the upper cloud fraction, clear area fraction, and low cloud fraction over the no-upper-cloud area separately for the daytime and nighttime orbit data. It is clear from the panels that the low cloud fraction over the no-upper-cloud area is larger during the nighttime than during the daytime by between $0 \%$ and $30 \%$, and the clear area fraction is smaller during the nighttime than during the daytime by between $0 \%$ and $30 \%$. A larger nighttime cloud fraction is consistent with previously described diurnal variations in low cloud over the ocean (e.g., Rozendaal et al. 1995). It is also interesting that the results show that the difference between the daytime and the nighttime is larger when the daytime solar elevation angle is larger. The difference is larger in the subtropics (off California: CALF, and off Peru: PERU) than in the mid-latitude areas. In the mid-latitudes, the difference is larger in summer than in winter; i.e., the difference is larger from April to
September for the Northern Hemisphere (NPAC, NWAT, and NEAT), and larger from October to March for the Southern Hemisphere (SOCN). These features are consistent with model simulations of the diurnal variations in MBLCs (Teixeira and Hogan 2002; Kawai and Inoue 2006).

The bottom panels in Fig. 8 show cloud top heights for both daytime and nighttime. It is clear from the panels that the nighttime cloud top height is higher than the daytime height in most months for all areas, and the difference between daytime and nighttime height values is $0-100 \mathrm{~m}$.

The diurnal cycles in the fraction of low clouds not covered by upper clouds (larger during the nighttime) and cloud top height (higher during the nighttime) might be affected by the difference in the detection ability of CALIPSO between daytime and nighttime. This is because CALIPSO uses a visible laser and its detection limit is influenced by daytime solar radiation. Therefore, the same calculation was performed using the CloudSat-only dataset $(\mathrm{C} 1)$ to examine the effect on the results shown in Fig. 8 of the drop off in low-cloud detection ability caused by solar radiation. This showed that the day-night differences obtained from the $\mathrm{C} 1$ dataset in the low cloud fraction over the no-upper-cloud area and in the cloud top heights between nighttime and daytime had characteristics 

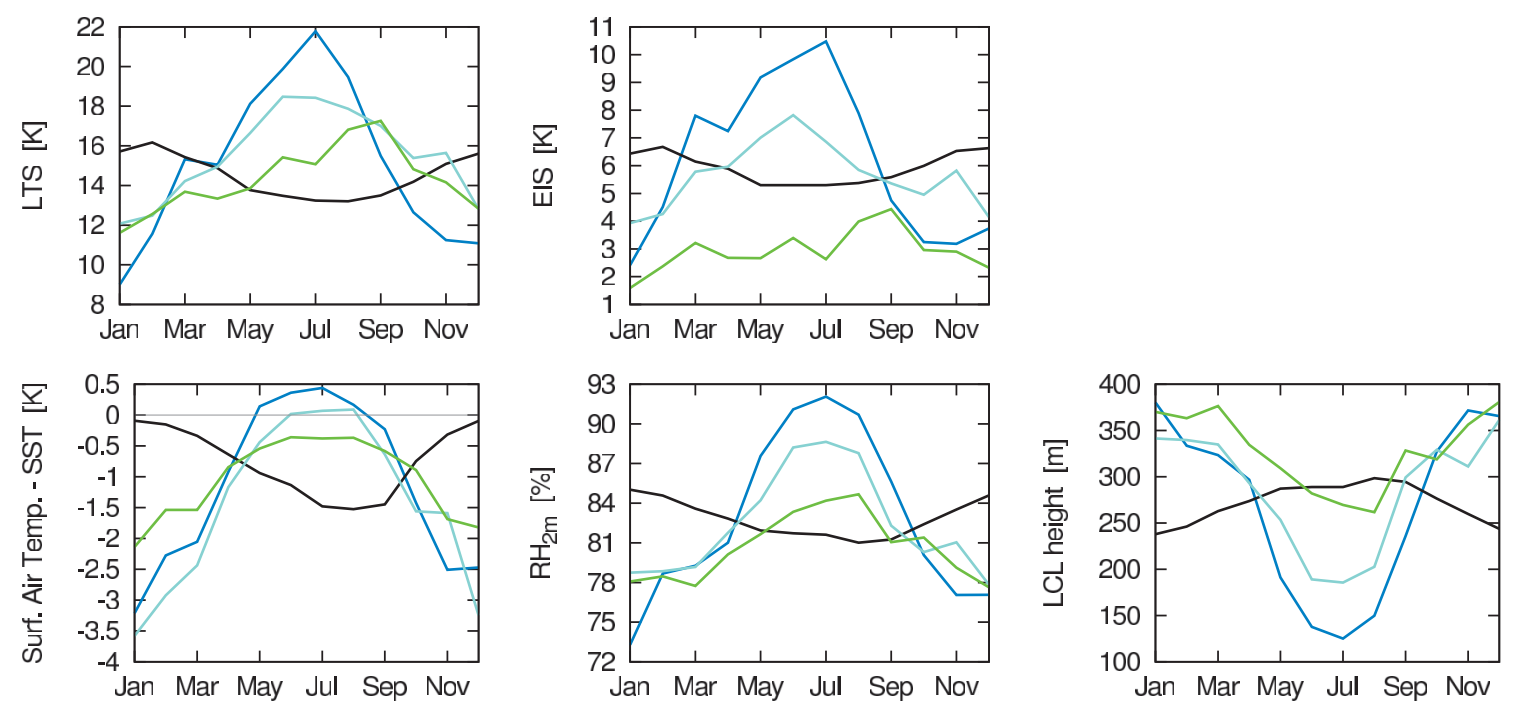

Fig. 9. Seasonal variations in LTS (top left), EIS (top right), temperature difference between the surface air and the sea surface (bottom left), relative humidity at $2 \mathrm{~m}$ (bottom middle), and lifting condensation level (bottom right) calculated from ERA-Interim data for the same areas plotted in Fig. 6.

similar to those from the $\mathrm{C} 2$ datasets (figures not shown). Therefore, we conclude that these differences between daytime and nighttime are not caused by the changing detection limits but reflect actual diurnal variations in the MBLCs.

\section{Discussion}

\subsection{Relationships with meteorological factors}

Although the main purpose of this paper is to summarize observational overviews related to characteristics of cloud top height of mid-latitude low clouds, a brief analysis of the relationship of cloud top height and fog frequency with the meteorological factors was performed with the aim of developing a better understanding of the causes of seasonal variations in cloud top heights and the frequency of fog outlined in Subsection 3.1. A number of meteorological factors were calculated from the ERA-Interim data, including the lower tropospheric stability (LTS; Klein and Hartmann 1993), estimated inversion strength (EIS; Wood and Bretherton 2006), vertical wind at $700 \mathrm{hPa}$, moist static energy vertical difference, difference between saturation moist static energy and moist static energy, meridional wind at $10 \mathrm{~m}$, sensible heat flux, latent heat flux, temperature difference between the surface air and the sea surface, relative humidity at $2 \mathrm{~m}$, and the lifting condensation level. Note that although more stability indexes than described above can be calculated (as in Kawai and Teixeira (2010)), they are correlated with each other and give similar correlation coefficients. The factors that were found to have a high correlation with cloud top height or fog frequency are discussed below.

\section{a. Cloud top height and meteorological factors}

The top panels in Fig. 9 show the seasonal variations in LTS and EIS. There are clear seasonal variations in both LTS and EIS for NPAC and NWAT, where they are large in summer and small in winter, whereas the amplitudes are small for NEAT and SOCN. The large seasonal variations for both NPAC and NWAT are caused mainly by the large seasonal amplitude of temperature at $700 \mathrm{hPa}$. Continents strongly heat the $700-\mathrm{hPa}$ air in summer but cool it strongly in winter, and this results in a stable lower troposphere in summer but an unstable one in winter over NPAC and NWAT in the Northern Hemisphere. In areas far from continents, such as NEAT in the Northern Hemisphere, the influence of the continents weakens, and the amplitude of the seasonal variations is small. No clear seasonal variations are seen in the Southern Hemisphere (SOCN) because the land coverage in the mid-latitudes is too small to significantly modify the air temperature.

The top panels in Fig. 10 show the scatter diagrams for cloud top height and stability indexes, in which data from the subtropics (off California and off Peru) are included. These panels show that the cloud top height of MBLCs has a high correlation with LTS ( $R=-0.83$, also $R=-0.83$ for mid-latitude data only) and EIS $(R=-0.73, R=-0.70$ for mid-latitude data only). These high correlations can be attributed to the 

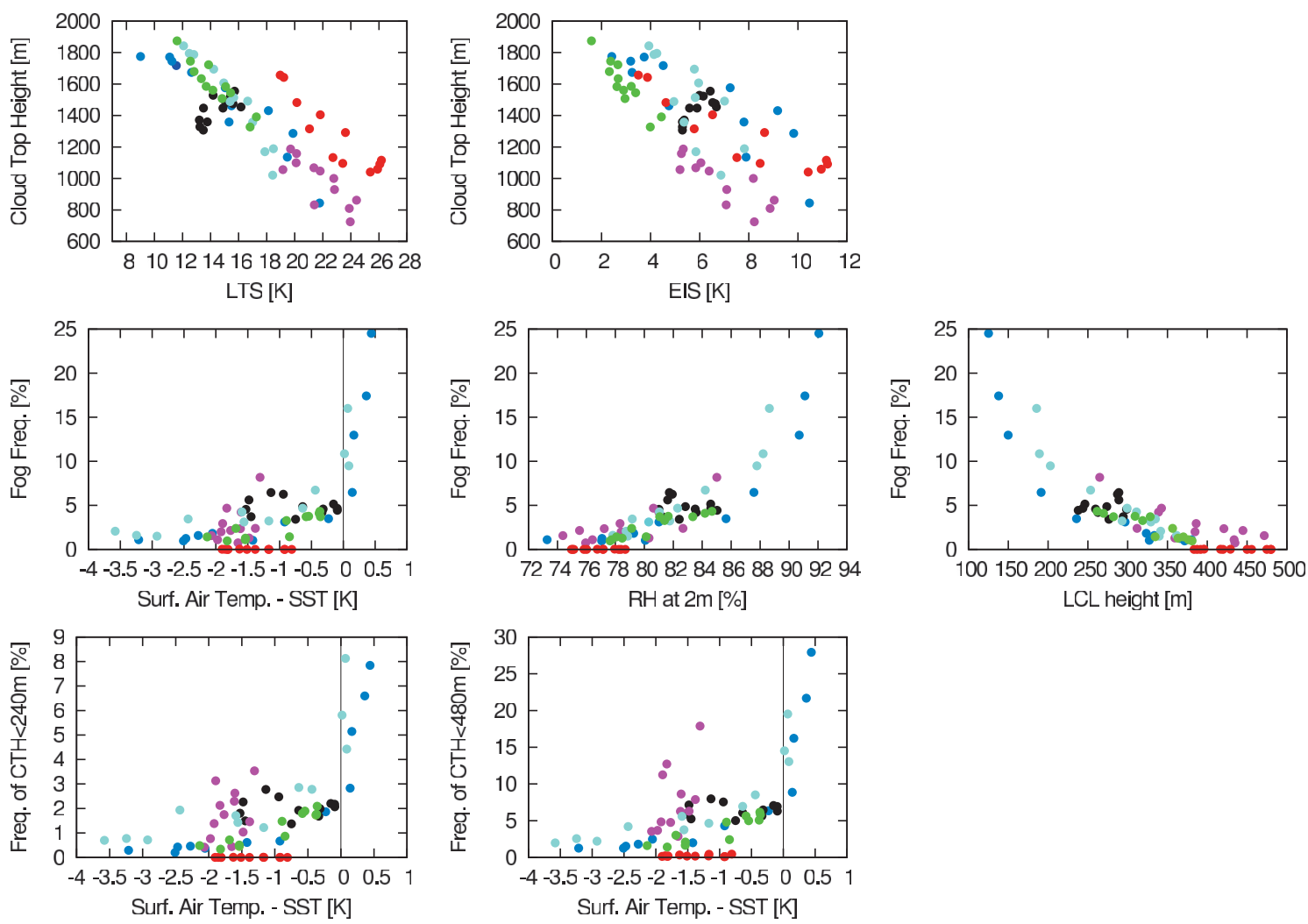

Fig. 10. The relationship of cloud top height with LTS (top left) and EIS (top right), and the relationship of fog frequency with temperature difference between the surface air and the sea surface (middle left), relative humidity at $2 \mathrm{~m}$ (middle middle), and lifting condensation level (middle right). The relationships of temperature difference between the surface air and the sea surface with occurrence frequencies of cloud top height below $240 \mathrm{~m}$ (bottom left) and $480 \mathrm{~m}$ (bottom right) are also plotted. The data used in Figs. 6 and 9 are plotted, and colors used are as in Fig. 6. Subtropical data (CALF (pink) and off PERU (orange), whose areas are shown in Fig. 4) are also plotted.

similar seasonal variations between cloud top height and LTS or EIS as described above. From the viewpoint of a comparison between the mid-latitudes and subtropics, the subtropical data essentially follow the same sequence as the mid-latitude data. The data for off California have a cloud top height in all seasons as low as the cloud top height in July over the North Pacific. Although it is well known that EIS is a better indicator of the cloud fraction of stratus and stratocumulus, especially when mid-latitude MBLCs are included (Wood and Bretherton 2006), the superiority of EIS over LTS was not found in the present study. Note that the established high correlation of EIS is not with cloud top height but with cloud fraction, and EIS can provide the estimated temperature gap at the inversion, but the inversion height cannot be determined from EIS and can be located at any altitude between the lifting condensation level and $700 \mathrm{hPa}$.
Nevertheless, the dispersions of the data in the panels cannot be ignored and the latitudinal variation in LTS or EIS in the North Pacific and the Southern Ocean (Fig. S2) cannot completely explain the latitudinal variations in cloud top height (Figs 7, S1). Therefore, further detailed analysis and discussion related to the factors controlling cloud top height and the associated mechanisms over the mid-latitudes will be necessary in the future but are outside the scope of this paper.

\section{b. Fog frequency and meteorological factors}

The bottom panels in Fig. 9 show the seasonal variations in temperature difference between the surface air and the sea surface, relative humidity at $2 \mathrm{~m}$, and the lifting condensation level. The temperature difference between the surface air and the sea surface is positive, relative humidity at $2 \mathrm{~m}$ is higher than about $87 \%$, and the lifting condensation level is below 200 
$m$ over NPAC and NWAT in summer. These characteristics can be interpreted as the result of warm air advection over an area of cold sea surface temperature (SST) by the subtropical high pressure systems during this season (Klein and Hartmann 1993).

The middle row of panels in Fig. 10 shows scatter diagrams of the fog frequency and surface parameters, showing that the fog frequency is high when the temperature difference between the surface air and the sea surface is positive, relative humidity at $2 \mathrm{~m}$ is higher than about $87 \%$, and the lifting condensation level is below $200 \mathrm{~m}$, which can occur only over NPAC and NWAT. Even when the temperature difference between the surface air and the sea surface is negative, relative humidity at $2 \mathrm{~m}$ is lower than about $87 \%$, and the lifting condensation level is above $200 \mathrm{~m}$, the correlation is positive for the temperature difference between the surface air and the sea surface, positive for relative humidity at $2 \mathrm{~m}$ and negative for the lifting condensation level in the mid-latitudes, although the slopes of the relationships are shallower. It is to be expected that the fog frequency is high when the surface air temperature is higher than the sea surface temperature, relative humidity at $2 \mathrm{~m}$ is high, and the lifting condensation level is low, as a result of warm air advection over a cold sea surface. The bottom panels in Fig. 10 show that the occurrence frequencies of cloud top height below $240 \mathrm{~m}$ and 480 $\mathrm{m}$ are closely correlated with the temperature difference between the surface air and the sea surface in the mid-latitudes as is the case for the fog frequency shown in the middle left panel. We can conclude from these results that at least the occurrence frequency of "near surface clouds," with cloud top height below $240 \mathrm{~m}$ or $480 \mathrm{~m}$, has a high correlation with the surface parameters in the mid-latitudes, even if we cannot draw the similar conclusion absolutely for fog, because the "fog" frequency obtained in the present study is the lower limit of the actual fog frequency. As for the subtropics, it should be noted that the mechanism of fog formation off California differs from that in mid-latitudes. Fog is produced off California not in association with warm surface air advection but with cold surface air advection. Here, the cloud layer with the inversion at the top is depressed by off-shore flow coming from inland over the coastal mountains (Koračin et al. 2014), the cloud layer is thickened by cloud top long wave cooling, and the cloud layer is observed as fog when the base attaches to the surface (Noonkester 1979).

It is important that these relationships described in this subsection are confirmed using global satellite data because this implies a large potential use for satellite data, which have much wider observational coverage and much higher observational frequency than in situ data including shipboard observations, for various studies related to fog.

\subsection{Diurnal variations in cloud top height}

Several studies have considered diurnal variations in the vertical structure of MBLCs for tropical or subtropical MBLCs using modeling (e.g., Duynkerke et al. 2004; Chlond et al. 2004) and observation (e.g., Betts (1990) and Blaskovic et al. (1991) for California coastal stratocumulus during the FIRE (first ISCCP regional experiment; Albrecht et al. 1988)). Clear diurnal variations in cloud top height were found in radiosonde data collected during the EPIC (East Pacific Investigation of Climate) field campaign (Bretherton et al. 2004; Caldwell et al. 2005), the maximum of which occurred in the early morning and the minimum in the early evening, with an amplitude of approximately $200 \mathrm{~m}$. Similar results (i.e., cloud top height was higher in the early morning and lower in the late afternoon, with an amplitude of $160 \mathrm{~m}$ ) were obtained by de Szoeke et al. (2012) from cloud radar, radiosonde, and wind profiler data over the southeastern tropical Pacific Ocean along $20^{\circ} \mathrm{S}$. Burleyson et al. (2013) showed that cloud top height is high at night and low during the daytime by analyzing radiosonde observations from VOCALS-REx (the variability of American monsoon systems (VAMOS) ocean-cloud-atmosphere-land study regional experiment). Zuidema et al. (2009) used infrared channel data obtained from MODIS to demonstrate that the cloud top height is lower during the daytime and higher during the nighttime offshore from Peru, and that the diurnal amplitude locally reaches $250 \mathrm{~m}$.

The diurnal differences in cloud top height of MBLCs over the PERU area obtained by the present study are consistent with these previous studies, whose target areas were also similar areas in the subtropics. The important result of the present study is that the cloud top heights show a significant diurnal variation, not only over the subtropics but also over mid-latitudes; i.e., cloud top height is higher during the nighttime than the daytime. While a seasonal change in diurnal variations in low cloud fraction over the no-upper-cloud area is clear, a seasonal change in diurnal variations in cloud top height was difficult to detect with a statistical significance because the standard deviation of the data (ca. 50-100 m) is not small enough to discuss it. However, it is important that the diurnal variation in cloud top height of MBLCs over mid-latitudes was clearly shown for the first time using satellite lidar data in the present study.

There are several candidate processes that can cause a lower cloud top height during the daytime, e.g., a more stable boundary (or cloud) layer generated by solar radiation heating of the air, less cloud top entrainment, stronger subsidence, and evaporation 
of the upper parts of the cloud layer caused by radiative heating during the daytime. Some papers have discussed the mechanisms for creating diurnal variations in cloud top height of tropical or subtropical MBLCs. Wang and McFarquhar (2008) used large eddy simulations to show that solar radiative heating of water vapor and ozone stabilizes the boundary (or cloud) layer and reduces the cloud top height of tropical shallow cumulus during the daytime. Bretherton et al. (2004) and Caldwell et al. (2005) showed that stronger subsidence during the daytime corresponds to the lower cloud top height in the EPIC observations, and Caldwell et al. (2005) showed that weaker cloud top entrainment during the daytime also contributes to lower cloud top height. On the other hand, Ciesielski et al. (2001) found during ASTEX (the Atlantic Stratocumulus Transition Experiment) that the diurnal variation in vertical velocity is inconsistent with the diurnal variation in cloud top height.

In the first place, the fluctuation of vertical wind is much larger in the mid-latitudes than in tropical or subtropical MBLC areas (except summer season in NPAC), and clear relationships between the diurnal variations of vertical wind and cloud top height were not found in the present study using ERA-Interim data. It is possible that the mechanisms that generate the diurnal variation in cloud top height differ between the subtropics and mid-latitudes, and so the mechanism, especially over mid-latitudes, should be investigated closely in the future.

\section{Summary}

\subsection{Availability of the KU cloud mask data for low cloud studies}

The $\mathrm{C} 2$ data of KU cloud mask dataset (Hagihara et al. 2010, 2014), retrieved from CALIPSO data, were used to investigate mainly the cloud top heights of mid-latitude MBLCs, which have received less attention than those of subtropical MBLCs. These data were appropriate for the study of low clouds because aerosol signals are removed from the CALIPSO backscatter data by using a sophisticated algorithm to generate the cloud mask data. It was confirmed that (i) the distribution map of the cloud top of MBLCs for each altitude bin does not show any unrealistic characteristics and is consistent with existing knowledge related to the MBLC distribution, including at altitudes lower than $1 \mathrm{~km}$ (ii) the cloud top height data from west coast subtropical MBLCs capture the well-established feature of the cloud layers being low near the coasts and gradually increasing in elevation offshore, and (iii) the climatology of the lowest bin (0-240 m) of the cloud mask was similar to the climatologies of fog obtained from shipboard observations and from model simulations.

\subsection{Revealed characteristics of the cloud top height of mid-latitude MBLCs \\ a. Seasonal variations}

The seasonal variations in cloud top height of the mid-latitude MBLCs, which were previously difficult to observe, were revealed. The differences in the seasonal variation between the Northern and Southern hemispheres was demonstrated; for example, in the North Pacific, the cloud top height is high (up to $1800 \mathrm{~m}$ ) in winter but low (down to $800 \mathrm{~m}$ ) in summer, whereas there is no clearly defined seasonal variation in the Southern Hemisphere. In addition, seasonal variations in the frequency of fog occurrence were shown for several mid-latitude ocean areas; for example, fog frequently develops during the summer over the North Pacific and the northwest Atlantic.

\section{b. Relationships between cloud top height and mete- orological factors}

The relationships of cloud top height and the frequency of fog occurrence with meteorological factors were briefly investigated. We found high correlations between the cloud top height of MBLCs and stability indexes in the lower troposphere, including LTS and EIS: cloud top height is higher for lower stabilities. This is one of the important results of the present study because the relationships between cloud top heights and meteorological parameters have not been closely studied, especially on a global scale including mid-latitudes, whereas the relationship between cloud fraction and stability indexes have been studied well (e.g., Klein and Hartmann 1993; Wood and Bretherton 2006).

The frequency of fog occurrence is closely correlated with the temperature difference between the surface air and the sea surface, relative humidity at $2 \mathrm{~m}$, and the lifting condensation level; the fog frequency is high when the temperature difference between surface air and sea surface is positive, relative humidity at $2 \mathrm{~m}$ is higher than about $87 \%$, and the lifting condensation level is lower than $200 \mathrm{~m}$ as monthly climatological fields. Near-surface clouds whose cloud top height is lower than 240 or $480 \mathrm{~m}$ also have a high correlation with these surface parameters.

\section{c. Latitudinal variations over the Southern Ocean}

Latitudinal variations in cloud top height during the summer and winter over the Southern Ocean were compared with those over the North Pacific. The cloud top height is higher over the Southern Ocean during the austral summer than over the North Pacific (ca. $850 \mathrm{~m}$ ) during the boreal summer, and becomes higher polewards between $40^{\circ} \mathrm{S}$ (ca. $1200 \mathrm{~m}$ ) to $65^{\circ} \mathrm{S}$ (ca. $1900 \mathrm{~m}$ ). The latitudinal variations are completely different between the Northern and Southern hemi- 
spheres, not only in summer but also in winter.

\section{d. Diurnal variations}

We have shown here that the cloud top height of mid-latitude MBLCs is $0-100 \mathrm{~m}$ higher at night than during the day and confirmed that this result was not because of the difference in the CALIPSO detection limit between night and day. The present study revealed that the diurnal variations in the cloud top height of mid-latitude MBLCs has the characteristics similar to those seen in subtropical MBLCs reported previously.

\subsection{Closing}

Previously, it has not been possible to investigate the vertical structure of mid-latitude MBLCs globally and in detail because conventional satellite data could not provide reliable information regarding these structures. We have shown in this paper that the KU cloud mask data retrieved from CALIPSO observations can be used to investigate the characteristics of the cloud top height of mid-latitude MBLCs in detail, for example, seasonal variations, latitudinal variations, the relationships with meteorological factors, and the differences between daytime and nighttime, as well as to investigate fog (or near surface clouds). Our results suggest that it will be possible to use this global data retrieved from satellites, with its much wider observation coverage and much higher observation frequency than that provided by in situ data (including shipboard observations), for more detailed global-scale studies of MBLCs. These data could also be used to evaluate mid-latitude MBLCs in global model simulations (e.g., Kawai et al. 2014). This paper has provided, for the first time, a comprehensive overview of the characteristics of the cloud top height of MBLCs and fog over the mid-latitudes that can be obtained from cloud mask data. The factors that control the cloud top height of mid-latitude MBLCs and the mechanisms that can explain, in particular, their latitudinal and diurnal variations should be revealed in increasing detail by future studies.

\section{Supplements}

Supplement 1 shows vertical section of the relative frequency of occurrence of cloud top height over the North Pacific and over the Southern Ocean. Supplement 2 shows latitudinal variations in LTS and EIS calculated from ERA-Interim data over the North Pacific and over the Southern Ocean.

\section{Acknowledgments}

The EECRA data were obtained from the Carbon Dioxide Information Analysis Center, Oak Ridge National Laboratory, US Department of Energy. The ECMWF ERA-Interim data used in this study were provided by ECMWF. The contact person for requesting the KU cloud mask data used in this study is Hajime Okamoto (okamoto@riam.kyushu-u.ac.jp). This research was partly supported by the Research Program on Climate Change Adaptation (RECCA) of the Ministry of Education, Culture, Sports, Science and Technology (MEXT), Japan. H. O. and Y. H. were supported by MEXT, Japan through grant-in-aid for Scientific Research A (25247078). We acknowledge the three anonymous reviewers for their constructive and insightful comments. The figures were edited by Rikako Matsumoto. Hirokazu Endo and Chiaki Kobayashi provided H. K. with useful comments regarding the data processing.

\section{References}

Abel, S. J., D. N. Walters, and G. Allen, 2010: Evaluation of stratocumulus cloud prediction in the Met Office forecast model during VOCALS-Rex. Atmos. Chem. Phys., 10, 10541-10559.

Ahlgrimm, M., and M. Köhler, 2010: Evaluation of trade cumulus in the ECMWF model with observations from CALIPSO. Mon. Wea. Rev., 138, 3071-3083.

Ahlgrimm, M., D. A. Randall, and M. Köhler, 2009: Evaluating cloud frequency of occurrence and cloud-top height using spaceborne lidar observations. Mon. Wea. Rev., 137, 4225-4237.

Albrecht, B. A., D. A. Randall, and S. Nicholls, 1988: Observations of marine stratocumulus clouds during FIRE. Bull. Amer. Meteor. Soc., 69, 618-626.

Betts, A. K., 1990: Diurnal variation of California coastal stratocumulus from two days of boundary layer soundings. Tellus A, 42, 302-304.

Blaskovic, M., R. Davies, and J. B. Snider, 1991: Diurnal variation of marine stratocumulus over San Nicolas Island during July 1987. Mon. Wea. Rev., 119, 14691478.

Bodas-Salcedo, A., K. D. Williams, P. R. Field, and A. P. Lock, 2012: The surface downwelling solar radiation surplus over the Southern Ocean in the Met Office model: The role of midlatitude cyclone clouds. $J$. Climate, 25, 7467-7486.

Bretherton, C. S., T. Uttal, C. W. Fairall, S. E. Yuter, R. A. Weller, D. Baumgardner, K. Comstock, and R. Wood, 2004: The EPIC 2001 stratocumulus study. Bull. Amer. Meteor. Soc., 85, 967-977.

Bretherton, C. S., R. Wood, R. C. George, D. Leon, G. Allen, and X. Zheng, 2010: Southeast Pacific stratocumulus clouds, precipitation and boundary layer structure sampled along $20^{\circ} \mathrm{S}$ during VOCALS-Rex. Atmos. Chem. Phys., 10, 10639-10654.

Burleyson, C. D., S. P. de Szoeke, S. E. Yuter, M. Wilbanks, and W. A. Brewer, 2013: Ship-based observations of the diurnal cycle of southeast Pacific marine stratocumulus clouds and precipitation. J. Atmos. Sci., 70, 3876-3894. 
Caldwell, P., C. S. Bretherton, and R. Wood, 2005: Mixedlayer budget analysis of the diurnal cycle of entrainment in southeast Pacific stratocumulus. J. Atmos. Sci., 62, 3775-3791.

Chlond, A., F. Müller, and I. Sednev, 2004: Numerical simulation of the diurnal cycle of marine stratocumulus during FIRE-An LES and SCM modelling study. Quart. J. Roy. Meteor. Soc., 130, 3297-3321.

Ciesielski, P. E., W. H. Schubert, and R. H. Johnson, 2001: Diurnal variability of the marine boundary layer during ASTEX. J. Atmos. Sci., 58, 2355-2376.

de Szoeke, S. P., S. Yuter, D. Mechem, C. W. Fairall, C. D. Burleyson, and P. Zuidema, 2012: Observations of stratocumulus clouds and their effect on the eastern Pacific surface heat budget along $20^{\circ} \mathrm{S}$. J. Climate, 25, 8542-8567.

Duynkerke, P. G., and J. Teixeira, 2001: Comparison of the ECMWF reanalysis with FIRE I observations: Diurnal variation of marine stratocumulus. J. Climate, 14, 1466-1478.

Duynkerke, P. G., S. R. de Roode, M. C. van Zanten, J. Calvo, J. Cuxart, S. Cheinet, A. Chlond, H. Grenier, P. J. Jonker, M. Köhler, G. Lenderink, D. Lewellen, C.-L. Lappen, A. P. Lock, C.-H. Moeng, F. Müller, D. Olmeda, J.-M. Piriou, E. Sánchez, and I. Sednev, 2004: Observations and numerical simulations of the diurnal cycle of the EUROCS stratocumulus case. Quart. J. Roy. Meteor. Soc., 130, 3269-3296.

Eastman, R., S. G. Warren, and C. J. Hahn, 2011: Variations in cloud cover and cloud types over the ocean from surface observations, 1954-2008. J. Climate, 24, 5914-5934.

Garay, M. J., S. P. de Szoeke, and C. M. Moroney, 2008: Comparison of marine stratocumulus cloud top heights in the southeastern Pacific retrieved from satellites with coincident ship-based observations. J. Geophys. Res., 113, D18204, doi:10.1029/2008JD009975.

Hagihara, Y., H. Okamoto, and R. Yoshida, 2010: Development of a combined CloudSat-CALIPSO cloud mask to show global cloud distribution. J. Geophys. Res., 115, D00H33, doi:10.1029/2009JD012344.

Hagihara, Y., H. Okamoto, and Z. J. Luo, 2014: Joint analysis of cloud top heights from CloudSat and CALIPSO: New insights into cloud top microphysics. J. Geophys. Res., 119, 4087-4106.

Hahn, C. J., and S. G. Warren, 2009: Extended edited synoptic cloud reports from ships and land stations over the globe, 1952-2009. ORNK/CDIAC-123, NDP-026C, Oak Ridge National Laboratory, Oak Ridge, TN, doi:10.3334/CDIAC/cli.ndp026c.

Haynes, J. M., C. Jakob, W. B. Rossow, G. Tselioudis, and J. Brown, 2011: Major characteristics of Southern Ocean cloud regimes and their effects on the energy budget. J. Climate, 24, 5061-5080.

Holz, R. E., S. A. Ackerman, F. W. Nagle, R. Frey, S.
Dutcher, R. E. Kuehn, M. A. Vaughan, and B. Baum, 2008: Global Moderate Resolution Imaging Spectroradiometer (MODIS) cloud detection and height evaluation using CALIOP. J. Geophys. Res., 113, D00A19, doi:10.1029/2008JD009837.

Japan Meteorological Agency, 2013: Outline of the operational numerical weather prediction at the Japan Meteorological Agency, appendix to WMO technical progress report on the global data-processing and forecasting system and numerical weather prediction research. JMA, Tokyo, Japan. [Available at http://www.jma.go.jp/jma/jma-eng/jma-center/nwp/ outline2013-nwp/index.htm.]

Karlsson, J., G. Svensson, S. Cardoso, J. Teixeira, and S. Paradise, 2010: Subtropical cloud-regime transitions: Boundary layer depth and cloud-top height evolution in models and observations. J. Appl. Meteor. Climatol., 49, 1845-1858.

Kawai, H., and T. Inoue, 2006: A simple parameterization scheme for subtropical marine stratocumulus. SOLA, 2, 17-20.

Kawai, H., and J. Teixeira, 2010: Probability density functions of liquid water path and cloud amount of marine boundary layer clouds: Geographical and seasonal variations and controlling meteorological factors. $J$. Climate, 23, 2079-2092.

Kawai, H., S. Yabu, and Y. Hagihara, 2014: The evaluation of the vertical structures of marine boundary layer clouds over mid-latitudes. CAS/JSC WGNE Research Activities in Atmospheric and Oceanic Modelling/ WMO, 44, 0611-0612.

Klein, S. A., and D. L. Hartmann, 1993: The seasonal cycle of low stratiform clouds. J. Climate, 6, 1587-1606.

Koračin, D., C. E. Dorman, J. M. Lewis, J. G. Hudson, E. M. Wilcox, and A. Torregrosa, 2014: Marine fog: A review. Atmos. Res., 143, 142-175.

Koshiro, T., and M. Shiotani, 2014: Relationship between low stratiform cloud amount and estimated inversion strength in the lower troposphere over the global ocean in terms of cloud types. J. Meteor. Soc. Japan, 92, 107-120.

Noonkester, V. R., 1979: Coastal marine fog in Southern California. Mon. Wea. Rev., 107, 830-851.

Norris, J. R., 1998a: Low cloud type over the ocean from surface observations. Part I: Relationship to surface meteorology and the vertical distribution of temperature and moisture. J. Climate, 11, 369-382.

Norris, J. R., 1998b: Low cloud type over the ocean from surface observations. Part II: Geographical and seasonal variations. J. Climate, 11, 383-403.

Norris, J. R., and S. A. Klein, 2000: Low cloud type over the ocean from surface observations. Part III: Relationship to vertical motion and the regional surface synoptic environment. J. Climate, 13, 245-256.

Okamoto, H., T. Nishizawa, T. Takemura, H. Kumagai, H. Kuroiwa, N. Sugimoto, I. Matsui, A. Shimizu, S. 
Emori, A. Kamei, and T. Nakajima, 2007: Vertical cloud structure observed from shipborne radar and lidar: Midlatitude case study during the MR01/K02 cruise of the research vessel Mirai. J. Geophys. Res., 112, D08216, doi:10.1029/2006JD007628.

Okamoto, H., T. Nishizawa, T. Takemura, K. Sato, H. Kumagai, Y. Ohno, N. Sugimoto, A. Shimizu, I. Matsui, and T. Nakajima, 2008: Vertical cloud properties in the tropical western Pacific Ocean: Validation of the CCSR/NIES/FRCGC GCM by shipborne radar and lidar. J. Geophys. Res., 113, D24213, doi:10.1029/2008JD009812.

Platnick, S., M. D. King, S. A. Ackerman, W. P. Menzel, B. A. Baum, J. C. Riédi, and R. A. Frey, 2003: The MODIS cloud products: Algorithms and examples from Terra. IEEE Trans. Geosci. Remote Sens., 41, 459-473.

Rahn, D. A., and R. Garreaud, 2010: Marine boundary layer over the subtropical southeast Pacific during VOCALS-REx - Part 1: Mean structure and diurnal cycle. Atmos. Chem. Phys., 10, 4491-4506.

Rossow, W. B., and R. A. Schiffer, 1999: Advances in understanding clouds from ISCCP. Bull. Amer. Meteor. Soc., 80, 2261-2287.

Rozendaal, M. A., C. B. Leovy, and S. A. Klein, 1995: An observational study of diurnal variations of marine stratiform cloud. J. Climate, 8, 1795-1809.

Stephens, G. L., D. G. Vane, S. Tanelli, E. Im, S. Durden, M. Rokey, D. Reinke, P. Partain, G. G. Mace, R. Austin, T. L'Ecuyer, J. Haynes, M. Lebsock, K. Suzuki, D. Waliser, D. Wu, J. Kay, A. Gettelman, Z. Wang, and R. Marchand, 2008: CloudSat mission: Performance and early science after the first year of operation. J. Geophys. Res., 113, D00A18, doi:10.1029/2008JD009982.

Teixeira, J., 1999: Simulation of fog with the ECMWF prognostic cloud scheme. Quart. J. Roy. Meteor. Soc., 125, 529-552.

Teixeira, J., and T. F. Hogan, 2002: Boundary layer clouds in a global atmospheric model: Simple cloud cover parameterizations. J. Climate, 15, 1261-1276.
Teixeira, J., S. Cardoso, M. Bonazzola, J. Cole, A. DelGenio, C. DeMott, C. Franklin, C. Hannay, C. Jakob, Y. Jiao, J. Karlsson, H. Kitagawa, M. Köhler, A. Kuwano-Yoshida, C. LeDrian, J. Li, A. Lock, M. J. Miller, P. Marquet, J. Martins, C. R. Mechoso, E. V. Meijgaard, I. Meinke, P. M. A. Miranda, D. Mironov, R. Neggers, H. L. Pan, D. A. Randall, P. J. Rasch, B. Rockel, W. B. Rossow, B. Ritter, A. P. Siebesma, P. M. M. Soares, F. J. Turk, P. A. Vaillancourt, A. von Engeln, and M. Zhao, 2011: Tropical and subtropical cloud transitions in weather and climate prediction models: The GCSS/WGNE Pacific Cross-section Intercomparison (GPCI). J. Climate, 24, 5223-5256.

Trenberth, K. E., and J. T. Fasullo, 2010: Simulation of present-day and twenty-first-century energy budgets of the Southern Oceans. J. Climate, 23, 440-454.

Wang, H., and G. M. McFarquhar, 2008: Large-eddy simulations of the diurnal cycle of shallow convection and cloudiness over the tropical Indian Ocean. Quart. J. Roy. Meteor. Soc., 134, 643-661.

Wang, L., Y. Wang, A. Lauer, and S.-P. Xie, 2011: Simulation of seasonal variation of marine boundary layer clouds over the eastern Pacific with a regional climate model. J. Climate, 24, 3190-3210.

Warren, S. G., C. J. Hahn, J. London, R. M. Chervin, and R. L. Jenne, 1988: Global distribution of total cloud cover and cloud type amounts over the ocean. NCAR/ TN-317+STR, National Center for Atmospheric Research, Boulder, USA.

Winker, D. M., M. A. Vaughan, A. H. Omar, Y. Hu, K. A. Powell, Z. Liu, W. H. Hunt, and S. A. Young, 2009: Overview of the CALIPSO mission and CALIOP data processing algorithms. J. Atmos. Oceanic Technol., 26, 2310-2323.

Wood, R., and C. S. Bretherton, 2006: On the relationship between stratiform low cloud cover and lower-tropospheric stability. J. Climate, 19, 6425-6432.

Zuidema, P., D. Painemal, S. de Szoeke, and C. Fairall, 2009: Stratocumulus cloud-top height estimates and their climatic implications. J. Climate, 22, 46524666. 